\title{
O Poder das Mídias Sociais Aplicadas em Iniciativas de Crowdfunding no Brasil
}

\author{
Fernanda Bruno dos Santos ${ }^{1}$, Ana Carolina Gama e Silva Assaife ${ }^{1}$ e Jonice \\ Oliveira ${ }^{1}$ \\ ${ }^{1}$ Programa de Pós Graduação em Informática \\ Universidade Federal do Rio de Janeiro (UFRJ) \\ Caixa Postal 68.530 - Rio de Janeiro - RJ - Brasil \\ \{fernanda.bruno, assaife\}@ufrj.br; jonice@dcc.ufrj.br
}

\begin{abstract}
The collective effort made by consumers via social media in order to raise funds to make an event possible is known for crowdfunding. This paper presents a study on the subject, showing a literature review and making an analysis using data collected from a number of different crowdfunding campaigns to answer the question: How and why consumers become participants in crowdfunding initiatives?
\end{abstract}

Resumo. O esforço coletivo realizado por consumidores através das mídias sociais com o objetivo de angariar fundos para tornar viável a realização de um evento é conhecido por 'crowdfunding'. Este artigo traz um estudo sobre o assunto, mostrando uma revisão de literatura sobre o tema. Através de dados extraídos de diversas campanhas, ele tenta responder a pergunta: Como e por que consumidores se transformam em participantes de iniciativas de 'crowdfunding'?

\section{Introdução}

Mídias Sociais são importantes ferramentas que usuários ao redor do mundo dispõem para se conectarem, trocarem experiências e compartilharem conteúdo de forma instantânea através da Internet. Com isso, conteúdos gerados por usuários atingiram alto grau de alcance através de seus comentários, críticas e recomendações que são lidos, compartilhados e discutidos em diversas plataformas disponíveis na Web. Tudo isso permitiu que pessoas com interesses semelhantes se aproximassem e participassem juntas em atividades.

A evolução da Web 2.0 e o crescimento de interatividade entre usuários favoreceram a transformação de como eles participam na mídia. Nos dias de hoje, o contato entre consumidores e marcas e entre artistas e fãs se tornou muito mais próximo. Se torna cada vez mais comum marcas buscarem feedback de seus consumidores a respeito de um produto ou bandas realizarem pesquisas a fim de saberem qual deve ser a próxima música a ser lançada como single no mercado.

Novos modos de circulação digital evidenciaram o poder das massas, conhecido como crowdfunding. Esse modelo usa as massas para obter idéias, feedbacks e soluções a fim de desenvolver de atividades de forma mais satisfatória. Porém, muitas vezes, os desejos das massas não podem ser atendidos por falta de recursos e com isso surgiu a idéia de buscar apoio financeiro através de pessoas comuns. O objetivo deste modelo é 
levantar fundos a fim de viabilizar algo de maneira independente, sem precisar exclusivamente de apoios ou patrocínios. Isso é realizado com apoio de mídias sociais e em particular através da Internet. De acordo com Brabham (2008), o desenvolvimento da Web 2.0 é um fator importante que facilita o encontro com as massas. Desse modo, ela torna mais simples a interação entre usuários que é uma característica crucial para que uma rede de investidores possa ser facilmente acessada.

O modelo de crowdfunding está relacionado ao conceito de cidade inteligente. Uma cidade inteligente tem como forte aspecto ser eficiente em como uma cidade funciona. Todo o seu planejamento tem como objetivo promover o crescimento social, ambiental e econômico através de informações diversas obtidas de vários pontos da cidade e de seus cidadãos. Ou seja, a "multidão" está atuando na coleta ou produção de dados, bem como participando de ações coletivas para o crescimento econômico, social e cultural da cidade. Neste ponto o crowdfunding se insere, fazendo do coletivo um mecanismo de investimento, convergindo os interesses em rentabilidade.

O objetivo deste trabalho é analisar o fenômeno emergente de crowdfunding, através do comportamento dos investidores através das mídias sociais. Este artigo trará uma visão desses projetos ao redor do mundo, mostrando o estado da arte envolvendo este modelo. Além disso, serão mostrados dados extraídos durante uma campanha do projeto de crowdfunding brasileiro Queremos a fim de avaliar os efeitos das mídias sociais no Brasil bem como processo de arrecadação e divulgação de um evento do grupo.

\section{Revisão de Literatura}

O modelo que o crowdfunding propõe é transformar o usuário de mídias sociais em investidores através de um processo de levantamento de fundos para tornar possível a realização de um certo evento, seja ele um produto ou um serviço. Através disso, o usuário está efetivamente participando da viabilização de algo que ele acredita e deseja.

A grande evidência para a disposição das pessoas para dar apoio financeiro a alguém em quem acreditam pode ser visto através do sucesso de Obama com a angariação de fundos para sua campanha presidencial em 2008 [Mangold and Faulds 2009]. A partir daí, percebeu-se o poder que as pessoas comuns, agora não vinculados apenas a grandes empresas, tinham de viabilizar projetos através da arrecadação de recursos. Com isso, o processo ganhou popularidade e se difundiu através da Web de forma efetiva [Belleflamme and Lambert 2011]. Este fenômeno pode ser observado pelo crescimento de iniciativas do gênero como Kickstarter $^{1}$ e Sellaband ${ }^{2}$. Grande parte dessas iniciativas é focada na área das artes, ou seja, relacionada com filmes e música.

Os trabalhos existentes na literatura estão relacionados tanto a fatores psicológicos quanto computacionais no que diz respeito ao tema. Quanto ao primeiro, existem estudos referentes à psicologia de massas e ao comportamento na realização de doações [Russ 2007]. Quanto aos aspectos computacionais, com a evolução da Web 2.0 os computadores puderam oferecer novas funcionalidades aos seus usuários, como a automatização de processos, que foram fundamentais para a consolidação do

\footnotetext{
${ }^{1}$ http://www.kickstarter.com

${ }^{2}$ http://www.sellaband.com
} 
crowdsourcing com suas redes virais de marketing e transações financeiras online [Kozinets, Hemetsberger and Schau 2008].

Existem ainda trabalhos referentes ao princípio da "wisdom-of-the-crowd" que se baseia na idéia de usar a comunidades disponíveis na Internet para ajudar na resolução de problemas e outras tomadas de decisão, tanto no domínio privado quanto público. Há uso desse princípio no universo acadêmico no campo da pesquisa e desenvolvimento [O’Neil 2010] e no coorporativo através da gerência de conhecimento das empresas [Oinas-Kukkonen 2008].

Através da revisão de literatura, foi observado o crescimento de trabalhos envolvendo o tema ao longo do tempo. Isso é um forte indício de que o assunto está sendo explorado e que já se tem um conhecimento consolidado sobre suas estruturas e perfis de projetos existentes. Este trabalho propõe uma análise diferenciada pois utiliza dados obtidos durante campanhas de crowdfunding de modo a traçar perfis de apoiadores e começar a entender como esses apoiadores interagem a fim de responder a pergunta: como e por que consumidores se transformam em participantes de iniciativas de crowdfunding?

\section{Estudo de Caso}

O objeto de estudo deste artigo é a iniciativa de crowdfunding brasileira "Queremos". Este projeto foi escolhido para análise pois, até o momento, todos os projetos criados por ela atingiram seus objetivos. Além disso, a iniciativa foi criada e desenvolvida no Brasil, um país de economia emergente e em que o financiamento de produtos ainda não se consolidou, e a capitalização de empresas é praticamente inexistente [Baer 2008].

\subsection{Descrição do Cenário}

O Queremos surgiu em 2010 em consequência dos eventos internacionais, sobretudo shows, que estavam vindo ao Brasil, mas não à cidade do Rio de Janeiro. Com a justificativa de que a razão da exclusão da cidade era o desinteresse do público, um grupo de cinco amigos, entre 25 e 30 anos e residentes na cidade do Rio de Janeiro, resolveu fazer algo a respeito e criaram o Queremos com o objetivo de dividir por uma fatia do público o valor necessário para produção de um evento, garantindo assim a sua realização. Com um importante diferencial: os apoiadores têm direito a um reembolso proporcional a venda de ingressos regulares, podendo ir de zero até ao valor integral. Esse apoiadores receberam o nome de "cariocas empolgados".

Para que está análise fosse possível, foram extraídos dados das mídias sociais Twitter $^{3}$ e Facebook ${ }^{4}$, bem como dados da página do projeto, durante o andamento de todas suas 20 campanhas de arrecadação. Através destas plataformas foram extraídos comentários, tweets e sinalizações de like. Além disso, foram obtidos dados de vendagem de ingressos reembolsáveis, lista de apoiadores bem como de empresas que colaboraram com o evento em questão.

\footnotetext{
${ }^{3}$ http://www.twitter.com/queremos

${ }^{4} \mathrm{http}: / /$ www.facebook.com/queremos.com.br
} 


\subsection{Análise do Resultado}

Através das análises realizadas, pode-se obter dados como total de fundos levantados, cerca de 700 mil dólares ao decorrer de 20 campanhas em 15 meses. Isso representa mais de 7 mil ingressos reembolsáveis vendidos que correspondem ao total de ingressos reembolsáveis colocados a disposição do público para compra antecipada. Desses ingressos, $62 \%$ foram vendidos para apoiadores físicos, que obtiveram reembolso total de seus investimentos em $60 \%$ dos eventos. Isso indica que, em média, esses investidores desembolsaram 16 dólares em cada show realizado pela iniciativa. Isso representa um preço bastante abaixo da média do valor de um ingresso de show internacional no Brasil que é de 80 dólares.

É importante mencionar que o projeto foi capaz de obter recursos de 21 empresas diferentes além do público durante todas as campanhas do projeto. Isso dá uma média de 1,05 empresas por show que apoiaram Queremos. Os bilhetes reembolsáveis comprados por essas empresas funcionam como marketing e contam como uma venda de ingressos de bilheteria, ou seja, o dinheiro arrecadado não é reembolsável. Devido à visibilidade dada durante o projeto, $43 \%$ das empresas compraram ingressos em mais de uma campanha e $24 \%$ delas em mais de duas, provando que associar à marca a idéia de crowdfunding é bom para os negócios.

Um caso especial baseado no apoio de empresas é o Festival Eu Quero ${ }^{5}$. Em troca de ter seu nome associado ao evento, uma loja de roupas brasileira comprou 400 ingressos reembolsáveis, o que representa metade do disponível durante a campanha. $\mathrm{O}$ festival foi capaz de trazer para a cidade do Rio de Janeiro sete diferentes bandas divididas em dois dias. $\mathrm{O}$ evento esgotou os ingressos de bilheteria e inspirou uma coleção de verão da patrocinadora do evento baseada no festival. A campanha atraiu muito atenção da mídia e ajudou a mostrar mais uma vez o poder de crowdfunding.

O sucesso dos shows está intimamente relacionado com a divulgação realizada pelos apoiadores nas mídias sociais. Foram realizados cerca de 25 mil comentários no Facebook e Twitter envolvendo os eventos. Aquelas que obtiveram reembolso total dos ingressos para seus apoiadores concentraram $67 \%$ destes 25 mil comentários, atraindo atenção de investidores privados e novos apoiadores para a campanha.

Destes apoiadores, 58\% compraram ingressos reembolsáveis em mais de uma campanha realizada pelo Queremos e $43 \%$ deles compraram mais de um ingresso em uma mesma campanha. Isso mostra que o público é fiel a causa e está conquistando aos poucos novos adeptos a idéia. O público universitário faz parte de $41 \%$ desse grupo e são importantes semeadores da idéia uma vez que é uma parte da população que vêm crescendo no uso de redes sociais no Brasil nos últimos anos, além de possuíram ampla rede de contatos e amigos nestas plataforma [McNaughton 2011].

Esses dados nos ajudam a responder a questão principal de como e por que consumidores resolvem se engajar nas iniciativas de crowdfunding. Eles interagem de modo intenso através das mídias sociais buscando novos apoiadores e disseminando o conceito. O motivo principal para a participação é a sensação de participar na concepção de algo, ou seja, tornar concreta uma idéia que sem a mobilização dela e outras pessoas, não seria possível.

\footnotetext{
${ }^{5}$ http://www.euquerofestival.com.br
} 


\section{Conclusão}

O propósito deste artigo é apontar a importância do crowdfunding e como ele está se tornando um fenômeno de popularidade através do esforço coletivo para angariar fundos na realização de um certo evento.

Neste artigo pode ser observada a existência de iniciativa de sucesso em um país emergente como o Brasil, mostrando que o fenômeno não está relacionado apenas a países conhecidos como de primeiro mundo. Isso mostra a viabilidade da idéia em realizar não só shows e eventos relacionados com música, mas também iniciativas de outros tipos. Com um público ativo e com vontade de tirar uma idéia do papel e colocála em prática, essa idéia promete ser um fenômeno ainda maior nos próximos anos.

\section{Referências}

Baer, W. (2008). Bulletin of Latin American Research xix, 498 The Brazilian Economy: Growth and Development. Pages 223-240 Praeger.

Belleflamme, P., and Lambert, T. (2011). "Crowdfunding: Tapping the Right Crowd." In Corporate Finance 2002: 1-38. Elsevier.

Brabham, D. (2008) "Crowdsourcing as a Model for Problem Solving: An Introduction and Cases." Convergence: The International Journal of Research into New Media Technologies 14: 75-90.

Kozinets, R., Hemetsberger,A. and Schau,H.. (2008). "The Wisdom of Consumer Crowds: Collective Innovation in the Age of Networked Marketing." In Journal of Macromarketing 28, pages 339-354. SAGE

Mangold, W., and Faulds, D. (2009). "Social media: The new hybrid element of the promotion mix." In Business Horizons 42(4), pages 357-365. Elsevier

McNaughton, M. (2011) "Social Networking in Brazil: Facebook Overtakes Orkut; Usage of Twitter Nearly Doubles in 5 Months." The Realtime Report. http:/therealtimereport.com/2011/09/21/social-networking-in-brazil-facebookovertakes-orkut-usage-of-twitter-nearly-doubles-in-5-months/, December 2011

Oinas-Kukkonen, H. (2008). "Network analysis and crowds of people as sources of new organisational knowledge." In Knowledge Management: Theoretical Foundation, pages 173-189. Informing Science Press

O'Neil,M.(2010). "Shirky and Sanger, or the costs of crowdsourcing." In Journal of Science Communication 9, pages 1-6. SISSA

Russ, C. (2007). "Online Crowds - Extraordinary Mass Behavior on the Internet." In MEDIA '07 and I-SEMANTICS '07, pages 103-110. VHM 